\title{
Analysing the Impact of State Policies on Variety Shows in China
}

\author{
Yaorui Mao ${ }^{1, \dagger}$ Yankai Wang ${ }^{2, \dagger}$, Weichen Zhang ${ }^{3, \dagger, *}$ \\ ${ }^{1}$ Suzhou International Academy. \\ ${ }^{2} X i^{\prime}$ an Jiaotong university middle school. \\ ${ }^{3}$ Communication University of China, Nanjing. \\ *Corresponding author's e-mail: guanghua.ren@gecacademy.cn \\ These authors contributed equally.
}

\begin{abstract}
Today, variety shows have received widespread attention and have become an essential part of the cultural and entertainment life of the general public. At present, China's entertainment industry has taken shape, and the successful introduction of foreign programmes has led to the further development of the industry. For example, Zhejiang TV's Run, Run, Run was introduced from South Korea's SBS's RUNNING MAN and Hunan TV's Dad! Where are you going was introduced from South Korea's MBC's Dad! Where are you going. This is not conducive to the long-term development of Chinese TV entertainment programmes. This article focuses on the emergence of homogenization in the Chinese entertainment market in recent years and the policy adjustments made by the relevant authorities to improve it. There is a contradiction between the phenomenon of homogenization and China's current need for innovation in the entertainment sector, with the root of the conflict being ratings and profitability.
\end{abstract}

Keywords: TV industry, homogenization, the entertainment industry.

\section{INTRODUCTION}

With the rapid development of online communication, digital technology, and the emergence of new media platforms with video as the carrier, the entertainment program industry in China is showing rapid development. However, when we delve into some of the famous and popular entertainment programs of the past, especially variety shows, it is not difficult to find that many of the prototypes originated from abroad, such as the United States, the Netherlands, and South Korea. In the current fast-developing economy, people have higher demands and expectations on the speed and efficiency of TV entertainment programs in a high-intensity, high-stress lifestyle. In the face of rapidly changing market demands, entertainment producers have little time to think creatively and focus on established or ready-made formats. This has led to a homogenization of the Chinese entertainment market, which has also greatly limited the scope for original entertainment programmes.

The government was equally aware of the problem and took measures in 2011, but the relevant policies have failed to address the root causes over the past ten years. This has given us food for thought and has become a research question. Is the introduction of appropriate policies effective in managing the market? Most of the domestic research and literature on the entertainment sector has focused on developing the entertainment market itself, with less research on the impact of policies on the market. Therefore, we consider this study to be of distinct research value.

This paper will compare the overall program market before and after introducing the policy by examining the market share, broadcast ratio, ratings, and economic benefits of various programs to examine whether the policy is effective and whether the problem has been solved. The primary data sources are CSM, CTR, China Audio-Visual Data, and China's National Radio And Television Administration. The primary sources of literature are the State Administration of Radio, Film, and Television of China and Soosci.com. Through data analysis and literature review, we will summarise the entertainment industry policies and assess their effectiveness. 


\section{LITERATURE REVIEW}

With the development of the economy, people's demand for more and more entertainment has increased, which is reflected in the rapid development of the entertainment market in the last decade. Since the 1980s, China's variety shows have gone through the era of variety shows, games, and entertainment, and now the popular era of talent shows, with recording locations ranging from the studio to the outdoors, participants from the stars to the masses, and audience experience from acceptance to participation [1]. In the midst of fierce competition, mainland China's television variety shows have shown a trend towards marketization and homogenization. Many variety shows imitate the designs and models of foreign programs, failing to meet the diverse and personalized needs of viewers, and blindly replicating and failing to innovate to meet the aesthetic needs of Chinese viewers [2]. Homogenization leads to stagnation in content and format innovation and results in a waste of resources and aesthetic fatigue among viewers. There are three main reasons for homogenization: firstly, the introduction of high-quality television programs; secondly, the inadequacy of copyright protection laws and regulations; and thirdly, implementing successful programmes based on ratings [3]. In conjunction with the entertainment restriction order issued by Central Radio and Television [4, 5], we note the impact of policy regulation on the entertainment market. Some researchers have suggested that the restriction of prime time for programs by the State Administration of Radio and Television (SARFT) has not fundamentally addressed the homogenization of program broadcasting [6].

\section{THE NEED FOR REGULATORY POLICY}

With the enrichment of media types and mobile internet development, audiences' viewing behavior has been continuously diverted. According to CSM Media Research statistics on the number of hours of TV viewing per capita in recent years, in the first half of 2018, the average person nationwide watched 132 minutes of TV per day, down by more than half an hour from four years ago [7]. Despite this, watching TV programs is still the main form of leisure and entertainment in viewers' leisure time. It can be seen from Figure 1 that TV variety shows [8], as one of the critical factors driving viewership growth, have become an essential target for various TV stations and major production companies to compete for the market. According to statistics, 115 variety shows were launched in 2019 on just the five top-tier TV platforms: Hunan TV, Zhejiang TV, Dongfang TV, Jiangsu TV, and Beijing TV.

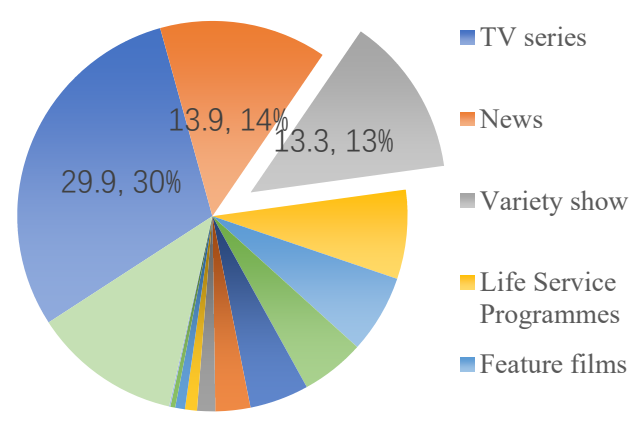

Figure 1. The ratio of viewing of various programs in the first half of 2020

Advertising investment is the primary source of profit for television stations. The growth in advertising profitability has a clear positive correlation with viewership, many stations have cut costs in the face of the rise of new media platforms, with viewership being the most important indicator. Every aspect of a new program is costly, such as time, production teams, money, and technology, and to achieve ratings in a short period. It has become the preferred choice of many stations to imitate the models of successful programs at low cost, leading to a proliferation of homogenization.

Homogenization was initially used in economics to refer to the convergence of products in terms of performance, appearance, marketing, etc. In the cultural field, homogenization refers to people's lifestyles and value pursuits to interact with each other, leading to cultural fusion and de-individualization. Expressly, in the film and television industry, we have noted the severe homogenization of Chinese variety shows. According to the data in Figure 2, viewers' comprehensive evaluation of variety shows can be summarised in the following aspects: 1. The phenomenon of following the trend is severe, and the format is single. 2. There is plagiarism and a lack of innovation.3.TV channels focus too much on ratings and neglect the cultural connotation of the programs [9]. 


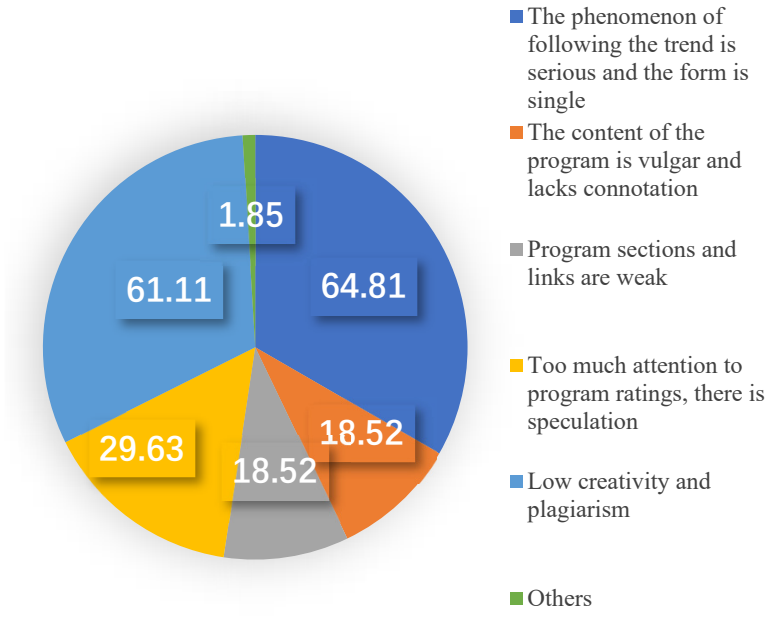

Figure 2 Views of Chinese variety shows public survey report

The lack of innovation is evident in the similarity of content, program formats, and similar names. The lack of innovation is evident in how programs are blindly copied without considering the actual needs of viewers, which will eventually lead to an abyss of homogenization.

\section{POLICY GAPS AND SHORTCOMINGS}

In 2017, the China Association of Network Audiovisual Program Services adopted the "General Rules for Auditing the Content of Network Audiovisual Programs". It states that network audiovisual programs, including network variety shows, need to be audited by the video website platforms themselves, and should follow the principle of first auditing before broadcasting and auditing in place[10]. However, the implementation of the audit system on video website platforms is not in place. Although the platforms have set up audit bodies by the policy, the audit process is not strict enough. Often the audit does not meet the standards, causing adverse effects, and the State Administration of Radio, Film, and Television (SARFT) has ordered broadcasters to take responsibility and takedown or rectify the content of the programs through post-tracing.

\section{THE ROLE AND IMPACT OF EFFECTIVE POLICIES}

The Opinions on Further Strengthening the Management of Programmes on Integrated TV Channels 2011 is the first time that the State Administration of Radio and Television has issued a document restricting the broadcasting of entertainment programs. The aim was to expand the proportion of news, economic, and cultural programmes on-air and restrict the airtime of seven entertainment programmes. This is also the first time the television industry has seen a "restriction on entertainment" [4].
In Table 1, we can see the change in viewership. As a result of the policy, the airtime of variety programs has decreased, the share of broadcast has decreased by almost $10 \%$, and the share of viewership has decreased by $2 \%$ [11]. To make a profit, satellite TV, which is dominated by various shows, has shifted to various programs. For viewers, they are also willing to pay attention to variety shows to reach the stars due to the reduction in variety shows. 2012 saw a 7\% increase in the share of variety shows.

Table 1. Broadcast proportion and audience rating proportion of some program types in 2011 and the first quarter of 2012

\begin{tabular}{ccccc}
$\begin{array}{c}\text { Program } \\
\text { type }\end{array}$ & \multicolumn{2}{c}{$\begin{array}{c}\text { Broadcast } \\
\text { proportion } \%\end{array}$} & \multicolumn{2}{c}{ Rating\% } \\
\cline { 2 - 5 } & $\begin{array}{c}\text { The first } \\
\text { Quarter } \\
\text { of } 2011\end{array}$ & $\begin{array}{c}\text { The first } \\
\text { quarter } \\
\text { of } 2012\end{array}$ & $\begin{array}{c}\text { The } \\
\text { first } \\
\text { quarter } \\
\text { of } 2011\end{array}$ & $\begin{array}{c}\text { The } \\
\text { first } \\
\text { quarter } \\
\text { of } 2012\end{array}$ \\
$\begin{array}{c}\text { Live } \\
\text { entertainm } \\
\text { ent }\end{array}$ & 21.19 & 10.78 & 28.43 & 26.73 \\
$\begin{array}{c}\text { Variety } \\
\text { show }\end{array}$ & 25.12 & 29.33 & 18.13 & 25.17 \\
& & & &
\end{tabular}

Figure 3 reflects the distribution of viewership of provincial TV variety programs throughout the day in the first quarter of 2011 and the first quarter of 2012 [12]. As can be seen from the data in the chart, the 21:00-22:00 time slot was the most concentrated time slot for viewers in the first quarter of 2011. the two adjacent time slots: 20:00-21:00 and 22:00-23:00, had a more even distribution of viewers, with little difference between them, and about half of the viewers were in the 21:0022:00 time slot. in the first quarter of 2012, the share of viewers for variety programs The share of viewers shrank, which was the main feature of the change. 21:00-22:00 time slot was still the most concentrated in 2012, but the viewership was significantly lower than in 2011. Using this time slot as the dividing line, the distribution of variety programs before 21:00 was lower in the first quarter of 2012 than in the same period in 2011. After $22: 00$, the distribution of variety programs grew significantly in the first quarter of 2012, with the time slot with the most significant change being 22:00-23:00, an increase of nearly one-third. 


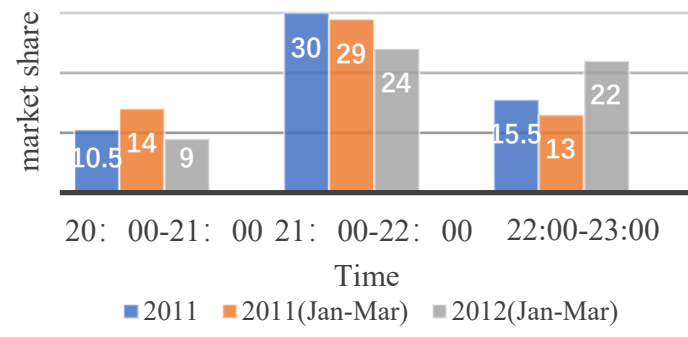

Figure 3. The distribution of all-day ratings of provincial TV variety shows in the first quarter of 2011 and 2012

In June 2016, to curb the phenomenon of blind introduction and overpriced introduction, the National Radio And Television Administration promulgated the Notice on Vigorously Promoting Independent Innovation in Radio and TV Programmes. It detailed regulations for giving independent innovation in programs. It stipulated that the number of programs with foreign copyright introduced on star channels on prime time stages must be limited to 2. Each year No more than one new program may be introduced from overseas [13]. To prevent the resurgence of imitation and plagiarism after introducing models has been restricted, the article also stipulates that "broadcasters must enhance their awareness of intellectual property rights, comply with legal provisions and market rules, and prevent plagiarism, imitation, and piracy." This move undoubtedly demonstrates the importance of "innovation" in the future market, like the Chinese National Radio And Television Administration of China (SAPPRFT) has issued several regulations that require all types of domestic variety shows to move in the direction of "creativity" and "innovation. The regulations have made it clear that all types of domestic variety shows must develop in the direction of "creativity" and "innovation". These regulations provide policy support to further reduce homogenization and further innovation and sublimation of cultural programs.

In September 2017, the National Radio And Television Administration of China issued the 13th FiveYear Development Plan for Press, Publication, Radio, Film, and Television, specifying the objectives, main tasks, and safeguards achieved by 2020 [14]. This includes the requirements of enhancing the dissemination, guidance, influence, and credibility of public opinion; comprehensively improving the level of public cultural services; enhancing the economic pulling effect; comprehensively promoting the "smart broadcasting" strategy and the transformation and upgrading of press and publication digitalization; improving the ability to safeguard national cultural security; spreading the voice of China, enhancing the image of China and letting products and services go global. The policy has influenced the development of China's image and its products and services. Influenced by the policy, Figures 4 and 5 show the comparative data of TV series and documentaries in 2017 and 2018 [15][16]. As shown in Figure 4, documentaries saw an increase of almost $27.3 \%$ in airtime in 2018 compared to 2017. In Figure 6, we can see that the number of TV dramas decreased by approximately $5.9 \%$ in 2018 compared to 2017. All these figures reflect that the State has restricted the production of TV dramas and encouraged the broadcasting of documentaries and historical films, thus correcting the initial proliferation of excessive entertainment, vulgar content, and web dramas in the TV industry.

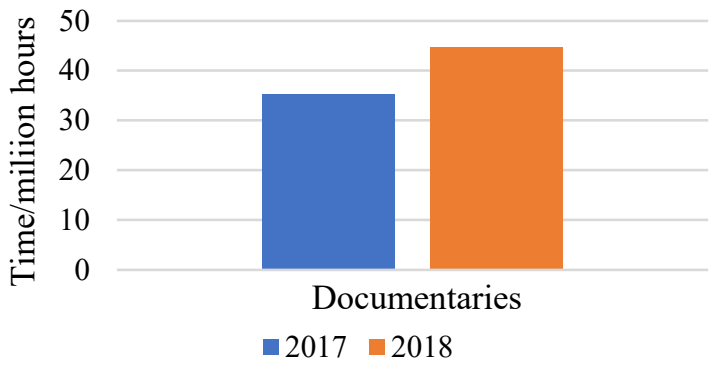

Figure 4. Comparative data of documentaries in 2017 and 2018

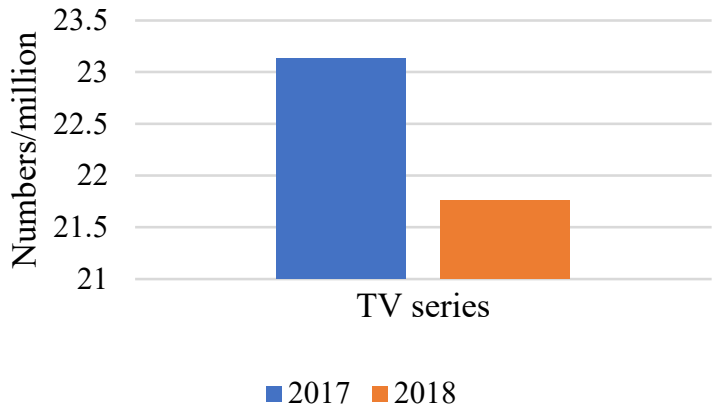

Figure 5. Comparative data of TV series in 2017 and 2018

In addition to ratings, advertising revenue is an essential indicator for the television industry that affects market conditions. In Figure 6, the data reflects a rapid increase in advertising revenue of almost $6.5 \%$ in 2013 [17], a general downward trend after 2014, a decline of almost 4.8\% in 2015, and a 'precipitous' decline in 2017 down by around $8.2 \%$ year-on-year. By 2018 , advertising revenue had fallen by $9.2 \%$ compared to 2012 . As the economy develops, advertising revenues, which are supposed to be on an upward trend, are in the opposite direction, so it is easy to see that government policy has effectively curbed the enormous profits of the entertainment industry, as well as dampening the attractiveness of homogenous programmes to advertisers. 


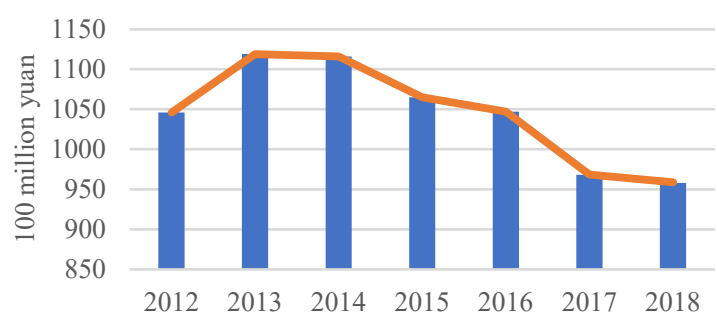

Figure 6. National TV advertising revenue from 20122018

In Figure 7, the data shows the change in viewing time per capita between 2012 and 2018 [18]. Using the first half of the year as the reference time, the time spent watching per capita has tended to decline year on year, except for 2016. 2016 was the only year in which it remained the same as the previous year. With the overhaul of the content of variety shows and the reduction in the number of TV dramas, people's enthusiasm for watching has gradually declined. From another perspective, the government has curbed the demand for entertainment programs, thus reducing the interests of entertainment program suppliers and investors.

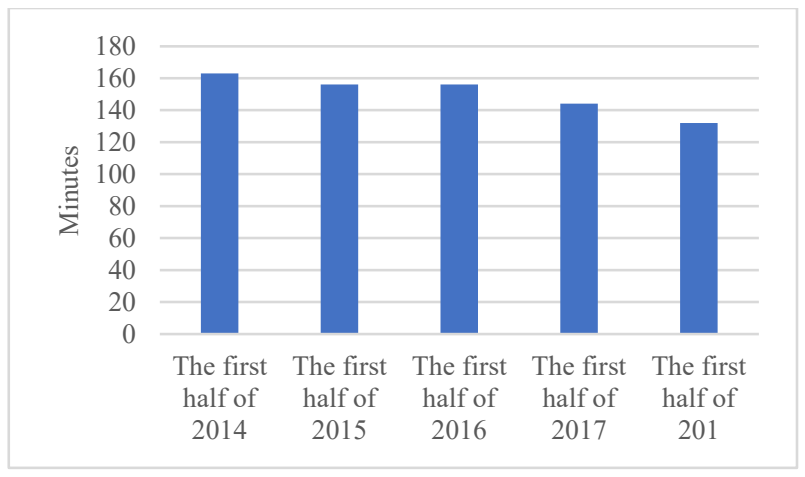

Figure 7. Viewing minutes per capita in the first half of 2014-2018

\section{CONCLUSION}

This article focuses on the emergence of homogenization in the Chinese entertainment market in recent years and the policy adjustments made by the relevant authorities to improve it. There is a conflict between the phenomenon of homogenization and China's current need for innovation in the entertainment sector, with the root of the conflict being ratings and revenue. As mentioned in the article, advertising is the primary source of revenue for entertainment programs, and advertising at this stage is often placed with traffic as the ultimate indicator. When the traffic generated by imitation is similar to or far exceeds the traffic generated by innovation, the value of innovation shrinks. Innovative program formats will face higher risks, more costly consumption, longer filming times, and homogenization when imitation, borrowing, or even copying can also generate good ratings.

In today's fast-growing economy, the high intensity and stressful pace of life and work have led to higher demands and expectations for the speed and efficiency of television entertainment production. Faced with the demands of a fast-changing market, entertainment producers are faced with a test of production speed, which greatly limits the space available for creating entertainment programs.

The phenomenon of homogenization is an inevitable process in developing media culture and a springboard for the development of independent brands of entertainment programmes. In the context of the globalization of China's entertainment industry, homogenization will not bring the development of the media market to a standstill. Still, it will instead prompt more programmes to take the initiative to develop innovations and improve their core competitiveness. In the short term, the emergence of homogenization can reduce costs and gain ratings quickly, providing direct aid to the survival of the media industry and enabling many companies, groups, and organizations in related industries to achieve good profit growth. However, in the long run, the emergence of homogenization reflects a series of problems in the market, such as value orientation, policy management, institutional development, and lack of innovation. Excessive homogenization can lead to a waste of viewing resources and make it difficult to meet the diverse needs of audiences.

At present, the homogenization of entertainment programmes in China has taken shape, and the introduction of new program genres has promoted the development of related industries. However, policy negligence has led to excessive imitation and copying of successful domestic entertainment programmes by some producers, which in turn has led to program homogenization, to the detriment of the long-term development of Chinese television entertainment programmes. To create greater progress and international competitiveness, changes must be made by the relevant entities. The Chinese entertainment industry is still in its infancy of development. It should actively explore a path that is in line with the flourishing development of the Chinese entertainment industry and develop a scientific mode of operation that is suitable for the Chinese entertainment industry.

\section{REFERENCES}

[1] Yushuai Chen, Research On TV Variety Shows Based On Agenda Setting Theory [M]. Central South UniversityInformation Science and Technology, 2011. vol. S1, pp. 15-22 
[2] Shuangzhi Su, Rethinking the Phenomenon Of TV Program Homogeneity [D]. Guangxi University, 2012.

[3] Ruiqi Mei, Analysis On The Homogeneity Of TV Variety Shows, Science And Technology Communication, 2018.

[4] National Radio And Television Administration of China, PRC, The State Administration Of Radio, Film And Television (SARFT) Will Strengthen The Management Of Satellite Comprehensive TV Programs, 2011.

[5] National Radio And Television Administration of China, PRC, Notice On The Compilation And filing Of TV Programs On Satellite Channels In 2014, 2013.

[6] Z. Li, S. Ma, Market Demand of Entertainment to Death and Restriction of Entertainment, Creative Communication, 2011.

[7] CSM media research, A Review Of The National TV Market In The First Half Of 2018, 2018.

[8] CSM media research, Ratio Of Viewing Of Various Programs In The First Half Of 2020, A Review Of The National TV Market In The First Half Of 2020, 2020.

[9] Questionnaire survey: Views of Chinese variety shows public survey report

[10] General Rules for Content Review of Online AudioVisual Programs, 2017.

[11] CSM media research, Broadcast proportion and audience rating proportion of some program types in 2011 and the first quarter of 2012, 2012.

[12] CSM media research, The distribution of all-day ratings of provincial TV variety shows in the first quarter of 2011 and 2012.

[13] National Radio And Television Administration of China, PRC, Notice on Vigorously Promoting Independent Innovation in Radio and TV Programmes, 2016.

[14] National Radio And Television Administration of China, PRC, the 13th Five-Year Development Plan for Press, Publication, Radio, Film and Television, 2017.

[15] CSM media research, Comparative data of documentaries in 2017 and 2018, 2018.

[16] CSM media research, Comparative data of TV series in 2017 and 2018, 2018.

[17] CSM media research, National TV advertising revenue from 2012-2018, 2018.
[18] CSM media research, Viewing minutes per capita, 2018. 